\title{
The Cathepsin B-Selective Inhibitors CA-074 and CA-074Me Inactivate Cathepsin L Under Reducing Conditions
}

\author{
Dietmar Steverding*
}

BioMedical Research Centre, Norwich Medical School, University of East Anglia, Norwich NR4 7TJ, UK

\begin{abstract}
The inhibitor CA-074 and its membrane-permeable derivative CA-074Me have been widely employed to study the biological function of cathepsin B. These compounds have been described as selective inactivators of cathepsin B with barely detectable action on other cathepsins. However, in this study it is demonstrated that CA-074 and CA-074Me also inactivate cathepsin $\mathrm{L}$ in the presence of the thiol reagents dithiothreitol and glutathione. In addition, it is also found that CA-074Me inactivates cathepsin B in the presence of dithiothreitol, an inhibition reaction previously not described. Furthermore, it is shown that CA-074 and CA-074Me are able to inhibit cathepsin L within living HL-60 cells and bloodstream forms of Trypanosoma brucei brucei. For HL-60 cells it is also shown that the inhibition of cathepsin L by the inhibitors is due to the reducing intracellular environment. These results suggest that CA-074 and CA-074Me are not suitable to discriminate between cathepsin B and L in vivo. Accordingly, previous demonstrations of the involvement of cathepsin B in physiological and pathological processes probably need re-evaluation.
\end{abstract}

Keywords: Cathepsin B, cathespin L, cathepsin B-selective inhibitors, enzyme inhibition, thiol reagents.

\section{INTRODUCTION}

Cathepsin B (EC 3.4.22.1) and L (EC 3.4.22.15) are well characterised lysosomal cysteine proteases present in all mammalian cells. They belong to the family $\mathrm{C} 1$ within the clan CA and share significant homology with papain, the archetypical cysteine protease of the family [1]. The main functions of cathepsin B and L are intracellular protein degradation/turnover, antigen presentation/processing, proenzyme activation, hormone maturation and epidermal homeostasis [2, 3]. However, when secreted, these lysosomal cysteine proteases can have adverse effects which can result in pathological conditions $[2,3]$. Cathepsin $\mathrm{B}$ in particular is involved in various diseases including cancer progression $[4,5]$, arthritis $[4,6,7]$ and pancreatitis [8]. In many of these studies, the highly selective inhibitor CA-074 and its methyl ester derivative CA-074Me (Fig. (1)) have been used to study the biological function of cathepsin $\mathrm{B}$ in vivo.

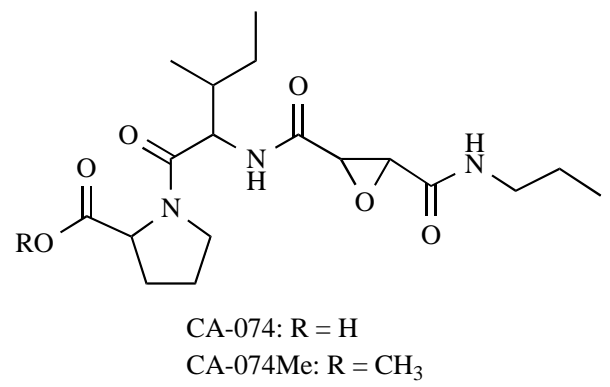

Fig. (1). Chemical structures of CA-074 and CA-074Me. CA$074 \mathrm{Me}$ is a cell-permeable methyl ester of CA-074.

*Address correspondence to this autor at the BioMedical Research Centre, Norwich Medical School, University of East Anglia, Norwich NR4 7TJ, UK; Fax: +44 1603 591750; Tel: +44 1603 591291;

E-mail: dsteverding@hotmail.com
Based on the natural peptidyl epoxide E-64 that irreversibly inhibits papain-like cysteine proteases, CA-074 was developed as a potent and specific inhibitor of cathepsin B [9]. This compound exhibits 77,000 times greater inhibitory effect on cathepsin B than on cathepsin L [9]. Although CA074 has been successfully used to discriminate between the activities of cathepsin B and cathepsin L in vivo [10], its carboxyl group may interfere with the passive diffusion of the compound across cellular membranes and, thus, render it useless. To overcome this limitation, CA-074Me was synthesised, a membrane-permeable derivative of CA-074 [11]. However, previously it was shown that CA-074Me inactivates both cathepsin $\mathrm{B}$ and cathepsin $\mathrm{L}$ within murine fibroblasts [12] raising doubts about the selectivity of the compound for cathepsin B in vivo.

In this study, the reason for the non-selectivity of CA$074 \mathrm{Me}$ in vivo was investigated and it was found that under reducing conditions $\mathrm{CA}-074$ and $\mathrm{CA}-074 \mathrm{Me}$ were also potent inhibitors of cathepsin L.

\section{MATERIALS AND METHODS}

\section{Materials}

Human cathepsin L, human cathepsin B, CA-074, CA$074 \mathrm{Me}$, DTT, GSH, BSO, DEM and AMC were from Sigma-Aldrich (Gillingham, U.K.). Z-FA-DMK was from Bachem (Weil am Rhein, Germany). Z-FR-AMC and Z-RRAMC were from BIOMOL (Exeter, U.K.).

\section{Cysteine Protease Activity Assay}

The catalytic activity of human cathepsin L, human cathepsin B, TbbCATL, TcrCATL and TbbCATB was determined in $100 \mathrm{mM}$ citrate, $\mathrm{pH} 5.0,2 \mathrm{mM}$ DTT using the fluorogenic substrates Z-FR-AMC and Z-RR-AMC at a concentration of $10 \mu \mathrm{M}$. After incubation for $10 \mathrm{~min}$ (purified enzymes and TbbCATL in trypanosome cell lysate), $60 \mathrm{~min}$ 
(TbbCATB in trypanosome cell lysate) or $90 \mathrm{~min}$ (cathepsin $\mathrm{L}$ in HL-60 cell lysate) at room temperature the reaction was stopped by adding iodoacetic acid to a final concentration of $2 \mathrm{mM}$. Release of free AMC was measured at excitation and emission wavelength of $360 \mathrm{~nm}$ and $460 \mathrm{~nm}$, respectively, in a BIORAD VersaFluor fluorometer. Data were calculated as specific activities (nmol AMC released/min) using a standard curve constructed with uncoupled AMC.

\section{Effect of CA-074 and CA-074Me on Cysteine Protease Activity}

The effect of CA-074 and CA-074Me on the catalytic activity of human cathepsin L, human cathepsin B, TbbCATL and TcrCATL was determined by pre-incubation

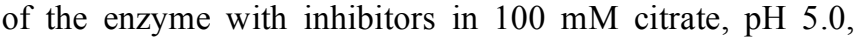
$10 \% \mathrm{DMSO}$, in the absence or presence of $1.4 \mathrm{mM}$ DTT or $4.2 \mathrm{mM}$ GSH. Controls contained DMSO alone. After $2 \mathrm{~h}$ incubation at room temperature, the enzymes were assayed for proteolytic activity.

\section{Cultivation of HL-60 Cells and Trypanosomes}

Bloodstream forms of Trypanosoma brucei brucei clone 427-221a [13] and human myeloid leukaemia HL-60 cells (LGC Promochem, Middlesex, UK) were grown in Baltz medium [14] and RPMI 1640 medium, respectively. Both media were supplemented with $16.7 \%(\mathrm{v} / \mathrm{v})$ heat-inactivated foetal calf serum and cultures were maintained in a humidified atmosphere containing $5 \% \mathrm{CO}_{2}$ at $37^{\circ} \mathrm{C}$.

Effect of CA-074, CA-074Me and Z-FA-DMK on Cathepsin L Activity within HL-60 Cells Pre-Treated with BSO and DEM

HL-60 cells were pre-treated for $24 \mathrm{~h}$ with $200 \mu \mathrm{M}$ BSO followed by $60 \mathrm{~min}$ with $1 \mathrm{mM}$ DEM. Thereafter, the cells $\left(1 \times 10^{6} / \mathrm{ml}\right)$ were incubated with $100 \mu \mathrm{M}$ CA-074 or CA$074 \mathrm{Me}$, in the presence of $1 \% \mathrm{DMSO}, 200 \mu \mathrm{M}$ BSO and 1 $\mathrm{mM}$ DEM at $37^{\circ} \mathrm{C}$. Control cultures were treated with $1 \%$ DMSO alone or with $100 \mu \mathrm{M}$ Z-FA-DMK in the presence of $200 \mu \mathrm{M}$ BSO and $1 \mathrm{mM}$ DEM. Untreated HL-60 cells $(1 \times$ $10^{6} / \mathrm{ml}$ ) were incubated with $100 \mu \mathrm{M} \mathrm{CA}-074$ or CA- $074 \mathrm{Me}$, in the presence of $1 \% \mathrm{DMSO}$ at $37^{\circ} \mathrm{C}$. Untreated control cultures were incubated with $1 \%$ DMSO alone or with 100 $\mu \mathrm{M}$ Z-FA-DMK. After $2 \mathrm{~h}$ incubation, cells were washed three times with PBS/1\% glucose and lysed in $100 \mathrm{mM}$ citrate, $\mathrm{pH} 5.0,2 \%$ Chaps $\left(10^{6}\right.$ cells $\left./ 100 \mu \mathrm{l}\right)$. Subsequently, the lysate was centrifuged and the clarified supernatant used to assay for proteolytic activity.
Effect of CA-074Me on Cysteine Protease Activity within Trypanosomes

Bloodstream forms of T. b. brucei $\left(1 \times 10^{7} / \mathrm{ml}\right)$ were incubated with different concentrations of CA-074Me in the presence of $1 \%$ DMSO at $37^{\circ} \mathrm{C}$. Control cultures were treated with $1 \%$ DMSO alone. After $2 \mathrm{~h}$ incubation, cells were washed three times with $\mathrm{PBS} / 1 \%$ glucose and lysed in $100 \mathrm{mM}$ citrate, $\mathrm{pH} 5.0,2 \%$ Chaps $\left(10^{7}\right.$ cells $\left./ 100 \mu \mathrm{l}\right)$. Subsequently, lysates were centrifuged and clarified supernatants used to assay for $T b b$ CATB and $T b b$ CATL activities.

\section{RESULTS AND DISCUSSION}

As the intracellular milieu is a reducing environment, the effect of thiol reagents on the inhibitory activity of CA-074 and CA-074Me on purified human cathepsin L was investigated. Pre-incubation of cathepsin L in the absence of any thiol reagents for $2 \mathrm{~h}$ with $100 \mu \mathrm{M}$ of the inhibitors resulted in only $12-15 \%$ inactivation of the enzyme (Table 1). This finding indicates, as expected, that both compounds are weak inhibitors for cathepsin L in vitro. However, if cathepsin L is pre-treated for $2 \mathrm{~h}$ with the inhibitors in the presence of 1.4 mM DTT, both CA-074 and CA-074Me inactivated the enzyme by greater than $98 \%$ compared to the respective control (Table 1). It should be noted that pre-incubation of cathepsin L with $1.4 \mathrm{mM}$ DTT for $2 \mathrm{~h}$ prevented its oxidative inactivation over time; controls treated with DTT showed a 4-fold higher activity than controls pre-incubated in the absence of any thiol reagent (Table 1). As GSH is the main reducing thiol within cells, the effect of this cellular antioxidant on the inhibitory activity of the inhibitors on cathepsin L was studied. In the presence of $4.2 \mathrm{mM} \mathrm{GSH}$ which is similar to the concentration of the thiol within cells [15], CA-074 and CA074Me inactivated cathepsin L by greater than $90 \%$ within 2 $\mathrm{h}$ (Table 1). This result shows that GSH is somewhat less effective than DTT in facilitating the inhibitory action of CA-074 and CA-074Me. The lower efficiency of GSH is further confirmed by the finding that GSH is less effective in preventing the oxidative inactivation of cathepsin $\mathrm{L}$ than DTT; controls pre-treated with $4.2 \mathrm{mM} \mathrm{GSH}$ for $2 \mathrm{~h}$ showed only a 2-fold higher activity than controls pre-treated without any thiol (Table 1). Also, the antioxidant ascorbic acid (vitamin C) had an effect on the inhibitory action of CA-074 on cathepsin L, although higher concentrations were needed and the impact was lower; pre-incubation of the enzyme with $100 \mu \mathrm{M} \mathrm{CA}-074$ for $2 \mathrm{~h}$ in the presence of $14 \mathrm{mM}$ ascorbic acid resulted in only $50 \%$ inhibition (data not shown).

In contrast to cathepsin $\mathrm{L}$, pre-treatment of cathepsin $\mathrm{B}$ with $100 \mu \mathrm{M}$ CA-074 in the absence of thiol reagents re-

Table 1. Effect of CA-074 and CA-074Me on the Activity of Human Cathespin $L$ in the Presence of Thiol Reagents

\begin{tabular}{|c|c|c|c|}
\hline \multirow{2}{*}{ Inhibitor } & \multicolumn{3}{|c|}{ Activity (nmol/min/ $\mathbf{\mu g}$ protein) } \\
\cline { 2 - 4 } & Control & + DTT & + GSH \\
\hline \hline DMSO & $111.3 \pm 15.5(100 \%)$ & $436.7 \pm 45.0(100 \%)$ & $241.0 \pm 46.1(100 \%)$ \\
\hline CA-074 & $98.7 \pm 25.0(88.7 \%)$ & $6.3 \pm 1.9(1.4 \%)$ & $18.7 \pm 6.1(7.8)$ \\
\hline CA-074Me & $94.7 \pm 24.4(85.1 \%)$ & $4.7 \pm 0.5(1.1 \%)$ & $22.7 \pm 5.0(9.4 \%)$ \\
\hline
\end{tabular}

Human cathepsin L $(2 \mu \mathrm{g} / \mathrm{ml})$ was pre-treated with DMSO, $100 \mu \mathrm{M} \mathrm{CA}-074$ or $100 \mu \mathrm{M} \mathrm{CA}-074 \mathrm{Me}$ in the presence or absence of $1.4 \mathrm{mM}$ DTT or $4.2 \mathrm{mM}$ GSH at room temperature, and $2 \mathrm{~h}$ later assayed for Z-FR-AMC hydrolysing activity. Data are the mean $\pm \mathrm{SD}$ of three experiments. 
Table 2. Effect of CA-074 and CA-074Me on the Activity of Human Cathespin B in the Presence of DTT

\begin{tabular}{|c|c|c|}
\hline \multirow{2}{*}{ Inhibitor } & \multicolumn{2}{|c|}{ Activity (nmol/min/ Con protein) } \\
\cline { 2 - 3 } & $295.4 \pm 27.8(100 \%)$ & $467.4 \pm 46.0(100 \%)$ \\
\hline \hline DMSO & $2.3 \pm 1.7(0.8 \%)$ & $1.0 \pm 0.9(0.2 \%)$ \\
\hline CA-074 & $294.9 \pm 31.6(99.8 \%)$ & $1.5 \pm 1.3(0.3 \%)$ \\
\hline CA-074Me & DTT \\
\hline
\end{tabular}

Human cathepsin B $(2.5 \mu \mathrm{g} / \mathrm{ml})$ was pre-treated with DMSO, $100 \mu \mathrm{M} \mathrm{CA}-074$ or $100 \mu \mathrm{M} \mathrm{CA}-074 \mathrm{Me}$ in the presence or absence of $1.4 \mathrm{mM}$ DTT at room temperature, and $2 \mathrm{~h}$ later assayed for Z-FR-AMC hydrolysing activity. Data are the mean \pm SD of three experiments.

Table 3. Effect of CA-074 on the Activity of TbbCATL and TcrCATL in the Presence of DTT

\begin{tabular}{|c|c|c|c|c|}
\hline \multirow{2}{*}{ Inhibitor } & \multicolumn{4}{|c|}{ Activity (nmol/min/ug protein) } \\
\cline { 2 - 5 } & \multicolumn{2}{|c|}{ TbbCATL (brucipain) } & \multicolumn{2}{c|}{ TcrCATL (cruzipain) } \\
\cline { 2 - 5 } & Control & Control & $86.3 \pm 15.9(100 \%)$ \\
\hline \hline DMSO & $89.3 \pm 22.6(100 \%)$ & $200.3 \pm 75.0(100 \%)$ & $30.3 \pm 3.1(100 \%)$ & $3.7 \pm 0.0(4.3 \%)$ \\
\hline CA-074 & $112.0 \pm 33.2(125 \%)$ & $2.7 \pm 0.5(1.3 \%)$ & $15.0 \pm 2.2(49.5 \%)$ & + DTT \\
\hline
\end{tabular}

$\operatorname{Tb} b \operatorname{CATL}(1.1 \mu \mathrm{g} / \mathrm{ml})$ and $T c r$ CATL $(20.1 \mu \mathrm{g} / \mathrm{ml})$ were pre-treated with DMSO (control) or with $100 \mu \mathrm{M}$ CA-074 in the presence or absence of $1.4 \mathrm{mM}$ DTT at room temperature, and $2 \mathrm{~h}$ later assayed for Z-FR-AMC hydrolysing activity. Data are the mean $\pm \mathrm{SD}$ of three experiments.

sulted in $99 \%$ inactivation of the enzyme while $100 \mu \mathrm{M} \mathrm{CA}-$ 074Me did not inhibit the enzyme at all (Table 2). This observation is in agreement with previous findings for the inhibitory activity of CA-074 and CA-074Me [11]. However, in the presence of $1.4 \mathrm{mM}$ DTT, not only CA-074 but also CA-074Me completely inactivated cathepsin B (Table 2). The ability of CA-074Me to react with cathepsin B in the presence of thiol reagents has not been described before. In addition, the prevention of oxidative inactivation over time of cathepsin B by DTT was not as pronounced as that observed for cathepsin L; controls pre-treated with $1.4 \mathrm{mM}$ DTT for $2 \mathrm{~h}$ displayed only a 1.6-fold higher activity than controls pre-incubated in the absence of the thiol.

The compound CA-074 does not only inhibit human cathepsin $\mathrm{L}$ under reducing conditions but also the cathepsin L homolog of Trypanosoma brucei brucei, TbbCATL (brucipain), and Trypanosoma cruzi, TcrCATL (cruzipain) (Table 3). Whereas the activity of TbbCATL is not at all inhibited by $100 \mu \mathrm{M}$ CA-074 in the absence of DTT, that of TcrCATL is inhibited by $50 \%$. The partial inhibition of TcrCATL is probably due to the fact that this peptidase also displays cathepsin $\mathrm{B}$ activity $[16,17]$. This additional activity was attributed to the presence of glutamate at the base of the S2 pocket (Glu 205) [16, 17]. The same residue is also found at the bottom of the S2 pocket in human cathepsin B [18]. In contrast, TbbCATL, like human cathepsin L, has an alanine residue at this position which renders this peptidase inactive for cathepsin B substrates [17]. Pre-incubation of both enzymes with $100 \mu \mathrm{M}$ CA-074 in the presence of 1.4 $\mathrm{mM}$ DTT, however, resulted in almost complete inhibition of the Z-FR-AMC hydrolysing activity. In addition, preincubation of TbbCATL and TcrCATL with $1.4 \mathrm{mM}$ DTT for $2 \mathrm{~h}$ prevented their oxidative inactivation over time; controls pre-incubated with the thiol showed a 2 to 3 -fold higher activity than controls pre-treated in the absence of DTT (Table 3).
The effect of CA-074 on the activity of cathepsin L in the presence of DTT was dependent on the concentration of the inhibitor (Fig. (2)). The $\mathrm{IC}_{50}$ value of CA-074 for the inhibition of cathepsin $\mathrm{L}$ in the presence of the thiol was determined to be $1.5 \mu \mathrm{M}$. As a result, the selectivity of CA-074 to inhibit cathepsin B compared to cathepsin $\mathrm{L}$ was reduced from $76,400\left(\mathrm{IC}_{50 \text { (cathepsin } \mathrm{L})}=172,000 \mathrm{nM}\right.$ [9] divided by $\mathrm{IC}_{50 \text { (cathespin B) }}=2.24 \mathrm{nM}$ [9]) under non-reducing conditions to $670\left(\mathrm{IC}_{50 \text { (cathepsin } \mathrm{L})}=1,500 \mathrm{nM}\right.$ (this study) divided by $\left.\mathrm{IC}_{50 \text { (cathespin } \mathrm{B})}=2.24 \mathrm{nM}[9]\right)$ under reducing conditions.

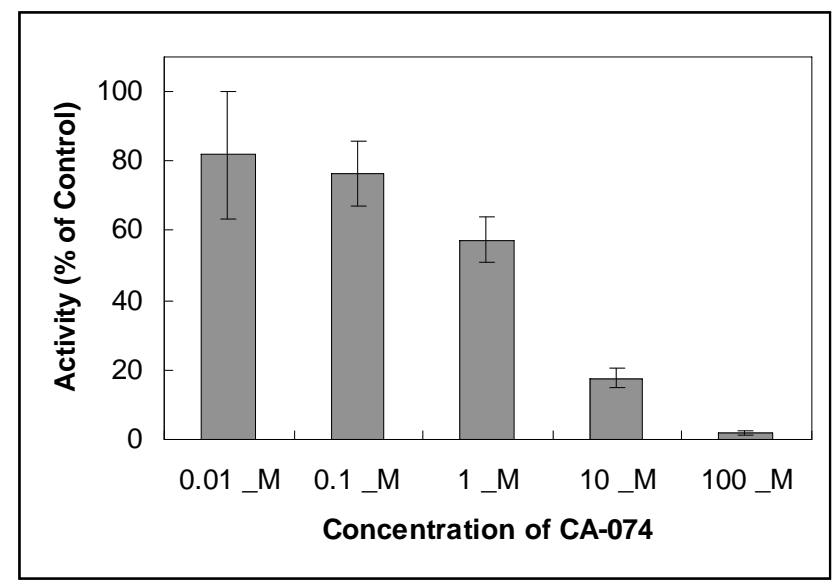

Fig. (2). Concentration-dependent effect of CA-074 on the activity of human cathespin L. The enzyme $(2 \mu \mathrm{g} / \mathrm{ml})$ was pre-treated with the indicated concentrations of CA-074 in the presence of $1.4 \mathrm{mM}$ DTT at room temperature, and $2 \mathrm{~h}$ later assayed for Z-FR-AMC hydrolysing activity. Data are the mean \pm SD of three experiments.

To see whether CA-074 and CA-074Me also inhibit cathepsin $\mathrm{L}$ in vivo, the effect of the compounds on the $\mathrm{Z}$ FR-AMC hydrolysing activity of HL-60 cells was investigated. Note that Z-FR-AMC is a fluorogenic substrate that is cleaved by most cathepsins including cathepsin $\mathrm{B}$ and $\mathrm{L}$ 
Table 4. Effect of CA-074, CA-074Me and Z-FA-DMK on the Cysteine Protease Activity in HL-60 Cells

\begin{tabular}{|c|c|c|}
\hline \multirow{2}{*}{ Inhibitor } & \multicolumn{2}{|c|}{ Activity $\left(\mathrm{nmol} / \mathrm{min} / 10^{6}\right.$ cells $)$} \\
\hline & - BSO/DEM & + BSO/DEM \\
\hline DMSO & $2.76 \pm 0.18(100 \%)$ & $1.43 \pm 0.12(100 \%)$ \\
\hline $100 \mu \mathrm{M} \mathrm{CA}-074$ & $0.54 \pm 0.05(19.6 \%)$ & $0.58 \pm 0.05(40.6 \%)$ \\
\hline $100 \mu \mathrm{M} \mathrm{CA}-074 \mathrm{Me}$ & $0.14 \pm 0.05(5.1 \%)$ & $0.17 \pm 0.01(11.9 \%)$ \\
\hline $100 \mu \mathrm{M}$ Z-FA-DMK & $0.12 \pm 0.04(4.3 \%)$ & $0.05 \pm 0.04(3.5 \%)$ \\
\hline
\end{tabular}

HL-60 cells were left untreated (- BSO/DEM) or incubated for $24 \mathrm{~h}$ with $200 \mu \mathrm{M}$ BSO followed by 60 min with $1 \mathrm{mM}$ DEM (+ BSO/DEM). Then, the cells were treated with the inhibitors in the absence or presence of BSO/DEM and $2 \mathrm{~h}$ later, cell extracts were prepared for assays of Z-FR-AMC hydrolysing activity. Data are the mean \pm SD of three experiments.

[19]. In order to differentiate between cathepsin B and L activity, the Z-FR-hydrolysing activity of HL-60 cells pretreated with or without BSO and DEM, two compounds that deplete cells of the thiol GSH [20], was compared. Whereas BSO is an inhibitor of $\gamma$-glutamylcysteine synthetase (the enzyme that catalyses the first step of glutathione synthesis), DEM reacts directly with the thiol and quickly decreases cellular GSH. Treatment of HL-60 cells for $24 \mathrm{~h}$ with 200 $\mu \mathrm{M}$ BSO followed by $60 \mathrm{~min}$ with $1 \mathrm{mM}$ DEM reduces the concentration of GSH by around 98\% [15]. HL-60 cells depleted of GSH showed a 2-fold lower Z-FR-AMC hydrolysing activity than untreated cells (Table 4). By contrast, when GSH-depleted HL-60 cells were incubated with $100 \mu \mathrm{M} \mathrm{CA}-$ 074 or CA-074Me, the Z-FR-AMC hydrolysing activity was unchanged compared to inhibitor-treated control cells (Table 4). Thus, the potency of CA-074 and CA-074Me to inhibit the Z-FR-AMC hydrolysing activity was reduced to around $59 \%$ and $88 \%$, respectively, in GSH-depleted cells (Table 4). It should be noted that CA-074Me is converted into CA-074 by intracellular esterases [11] and is, therefore, able to inhibit cathepsin B in GSH-depleted HL-60 cell. On the other hand, GSH-depleted HL-60 cells incubated with $100 \mu \mathrm{M}$ of the non-selective cysteine peptidase inhibitor Z-FA-DMK showed a 2-fold lower Z-FR-AMC hydrolysing activity than inhibitor-treated control cells (Table 4). This is the same reduction in activity as observed for DMSO-treated cells indicating that the inhibitory potency of Z-FA-DMK was unchanged in HL-60 cells depleted of GSH. This result confirms that the inhibitory action of CA-074 and CA-074Me to inactivate cathepsin L within HL-60 cells depends on the intracellular reducing thiol GSH.

As, in the absence of thiols, CA-074Me does not inhibit cathepsin L (see Table 1), the remaining Z-FR-AMC hydrolysing activity of about $12 \%$ observed in GSH-depleted HL60 cells treated with CA-074Me (see Table 4) should reflect the proportion of cathepsin L activity of the total Z-FR-AMC hydrolysing activity. In fact, this value is in good agreement with the relative contribution of cathepsin L to the Z-FRAMC hydrolysing activity which was determined to be $13.5 \%$ (Table 5). Hence, it could not be expected that the inhibitory effect of CA-074Me in GSH-depleted HL-60 cells would be lower than $86.5 \%$.

As HL-60 cells have only little cathepsin L activity, the effect of CA-074Me on TbbCATL in bloodstream forms of T. b. brucei was studied. Whereas TbbCATL is the major cysteine protease in $T . b$. brucei, TbbCATB, the cathepsin B homologue in $T$. b. brucei, is only a minor component [21]. The relative contribution of TbbCATL and TbbCATB to the total cysteine protease activity in bloodstream-form trypanosomes is approximately $82 \%$ and $18 \%$, respectively (Table 5). This means that with Z-FR-AMC it is mainly the TbbCATL activity that is measured, whereas with Z-RR$\mathrm{AMC}$, a fluorogenic substrate specific for cathepsin B [22], it is exclusively the $T b b \mathrm{CATB}$ activity that is quantified. Under the presumption that CA-074Me only inactivates cathepsin B and not cathespin L enzymes, one would expect that the Z-FR-AMC hydrolysing activity in $T$. b. brucei be only reduced by a maximum of $18 \%$ while the Z-RR-AMC hydrolysing activity should be completely inhibited when the cells are treated with the inhibitor. However, when bloodstream-form trypanosomes were incubated with CA-074Me in a concentration range varying from $1 \mathrm{nM}$ to $10 \mu \mathrm{M}$, a similar dose-dependent effect for both Z-FR-AMC and ZRR-AMC hydrolysing activity was observed (Fig. (3)). Up to a concentration of $100 \mathrm{nM}$, both activities were almost completely inhibited. Under the experimental conditions, $\mathrm{IC}_{50}$ values for the inhibition of TbbCATB and TbbCATL were 5 $\mathrm{nM}$ and $22 \mathrm{nM}$, respectively. This result confirms the findings obtained with HL-60 cells and indicates that CA-074Me is a potent inhibitor of cathepsin L enzymes within living cells.

Previously it was reported that the cathepsin B-selective inhibitor CA-074Me, but not its parental compound CA-074,

Table 5. Determination of the Relative Contribution of Cathepsin B and L in HL-60 Cells and Bloodstream Forms of T. b. brucei

\begin{tabular}{|c|c|c|}
\hline \multirow{2}{*}{ Inhibitor } & \multicolumn{2}{|c|}{ Activity (nmol/min/106 cells) } \\
\cline { 2 - 3 } & HL-60 cells & T. b. brucei \\
\hline \hline DMSO & $3.84 \pm 1.73(100 \%)$ & $33.15 \pm 5.72(100 \%)$ \\
\hline $100 \mu \mathrm{M} \mathrm{CA}-074 \mathrm{Me}$ & $0.52 \pm 0.16(13.5 \%)$ & $27.13 \pm 10.29(81.8 \%)$ \\
\hline
\end{tabular}

Cell extracts of HL-60 cells and bloodstream-form trypanosomes were treated with inhibitors or DMSO, and $2 \mathrm{~h}$ later assayed for Z-Phe-Arg-AMC hydrolysing activity. Note that in the absence of thiol reagent CA074Me does not inhibit the activity of human and T. b. brucei cathepsin L (see Tables 1 and $\mathbf{3}$ ). This means that the Z-Phe-Ala-AMC hydrolysing activity determined in the presence of $100 \mu \mathrm{M} \mathrm{CA}-074 \mathrm{Me}$ represents mainly the cathepsin L activity. Thus, the relative contribution of cathepsin B and L in HL-60 cells and trypanosomes is $86.5 \%$ and $13.5 \%$, and $18.2 \%$ and $81.8 \%$, respectively. Data are the mean \pm SD of three experiments. 


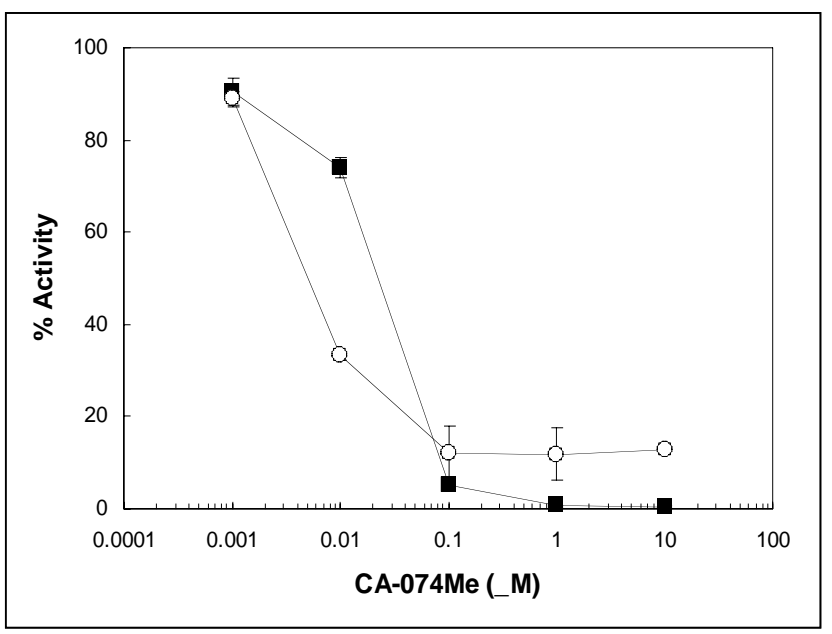

Fig. (3). Inhibitory effect of CA-074Me on the Z-Phe-Arg-AMC and Z-Arg-Arg-AMC hydrolysing activity in T. b. brucei bloodstream forms. Trypanosomes were incubated at a density of $10^{7}$ cells $/ \mathrm{ml}$ with varying concentrations of CA-074Me. After $2 \mathrm{~h}$ of incubation, cell extracts were prepared for assays of Z-Phe-ArgAMC (closed squares) and Z-Arg-Arg-AMC (open circles) hydrolysing activities. The experiment was repeated three time and mean values \pm SD are shown. Please note that the maximum achievable inhibition of the Z-Arg-Arg-AMC hydrolysing activity in bloodstream forms of $T$. b. brucei is $85-90 \%$ as was confirmed with the non-selective cysteine protease inhibitor Z-FA-DMK (data not shown).

also inactivates intracellular cathepsin L [12]. Based on this observation it was suggested that CA-074 rather than CA$074 \mathrm{Me}$ should be used to selectively inhibit cathespsin B within living cells [12]. However, no explanation was provided as to why CA-074Me and not CA-074 inhibits intracellular cathespin L. In this study it is now shown that CA074Me and CA-074 can inactivate intracellular cathepsin L and $T b b C A T L$. In addition, it is demonstrated that the inhibitory action of both compounds is due to the intracellular reducing milieu. This is corroborated by the finding that purified cathepsin L and other cysteine proteases are inhibited by CA-074Me and CA-074 in the presence of the thiols DTT and GSH. That the reducing agents react on the inhibitors can be excluded as epoxysuccinyl derivatives do not react with simple thiols [23]. It may be that the reduction of cysteine groups other than the active site cysteine residue by thiol reagents causes a conformational change of the protein so that the binding pocket of the enzyme is more accessible for the inhibitors. This hypothesis is supported by the observation that $\mathrm{CA}-074 \mathrm{Me}$ is able to inactivate cathepsin $\mathrm{B}$ in the presence of DTT but not in the absence of the thiol.

It has been suggested that $\mathrm{CA}-074 \mathrm{Me}$ is a proinhibitor that is converted into its active free carboxyl form, CA-074, by intracellular esterases upon internalisation [11]. This was concluded from the observation that methyl esterification of the carboxyl group of CA-074 abolished the inhibitory effect of the compound on cathepsin B [11]. This seems not to be true for the inactivation of cathespin $\mathrm{L}$ and $\mathrm{B}$ under reducing conditions. Both CA-074Me and CA-074 inhibit cathepsin L and $\mathrm{B}$ to the same extent in the presence of reducing thiols.

\section{CONCULSION}

The outcome of this study is very important because it shows that two inhibitors classically used to selectively inhibit cathespin B also inhibit cathespin L under reducing conditions. As the intracellular environment is reducing in nature, these results also suggest that many in vivo studies based on the use of CA-074 and CA-074Me are challenging. This means that previous demonstrations of the involvement of cathepsin B in physiological and pathological processes should be re-evaluated. The findings also show that results obtained with purified enzymes cannot always be applied to living systems without restriction.

\section{ACKNOWLEDGEMENTS}

I would like to thank Dr Darren Sexton (BioMedical Research Centre, School of Medicine, Health Policy and Practice, University of East Anglia, Norwich, U.K.) for critical reading of the manuscript and Dr Conor Caffrey (Sandler Center for Drug Discovery, California Institute for Quantitative Biosciences, University of California San Francisco, San Francisco, USA) for the generous gift of TbbCATL (brucipain) and $T c r$ CATL (cruzipain).

\section{ABBREVIATIONS}

\begin{tabular}{|c|c|}
\hline AMC & $=7$-amino-4-methylcoumarin \\
\hline BSO & $=\mathrm{L}$-buthionine- $(S, R)$-sulfoximine \\
\hline CA-074 & $\begin{aligned}= & \text { L-3-trans-(propylcarbamoyl)oxirane-2- } \\
& \text { carbonyl]-L-isoleucyl-L-proline }\end{aligned}$ \\
\hline CA-074Me & $\begin{aligned}= & \text { L-3-trans-(propylcarbamoyl)oxirane-2- } \\
& \text { carbonyl]-L-isoleucyl-L-proline methyl ester }\end{aligned}$ \\
\hline DEM & $=$ Diethyl maleate \\
\hline DMSO & $=$ Dimethyl sulfoxide \\
\hline DTT & $=$ DL-dithiothreitol \\
\hline GSH & $=$ Reduced glutathione \\
\hline TbbCAТВ & $=$ Trypanosoma brucei brucei cathepsin $\mathrm{B}$ \\
\hline TbbCATL & $=$ Trypanosoma brucei brucei cathepsin $\mathrm{L}$ \\
\hline TcrCATL & $=$ Trypanosoma cruzi cathepsin $\mathrm{L}$ \\
\hline Z-FA-DMK & $\begin{aligned}= & \text { benzyloxycarbonyl-phenylalanyl-alanyl } \\
& \text { diazomethane }\end{aligned}$ \\
\hline -FR-AMC & $\begin{aligned}= & \text { Benzyloxycarbonyl-phenylalanyl-arginyl-7- } \\
& \text { amido-4-methyl coumarin }\end{aligned}$ \\
\hline RR-AMC & $\begin{aligned}= & \text { Benzyloxycarbonyl-arginyl-arginyl-7- } \\
& \text { amido-4-methyl coumarin }\end{aligned}$ \\
\hline
\end{tabular}

\section{REFERENCES}

[1] Rawlings ND, Barrett AJ, Bateman A. MEROPS: the peptidase database. Nucleic Acids Res 2010; 38: D227-33.

[2] Turk B, Turk D, Turk V. Lysosomal cysteine proteases: more than scavengers. Biochim Biophys Acta 2000; 1477: 98-111.

[3] Lecaille F, Kaleta J, Brömme D. Human and parasitic papain-like cysteine proteases: their role in physiology and pathology and recent developments in inhibitor design. Chem Rev 2002; 102: 445988.

[4] Yan S, Sloane BF. Molecular regulation of human cathepsin B: implication in pathologies. Biol Chem 2003; 384: 845-54.

[5] Podgorski I, Sloane BF. Cathepsin B and its role(s) in cancer progression. Biochem Sco Symp 2003; 70: 263-76. 
[6] Baici A, Lang A, Zwicky R, Müntener K. Cathepsin B in osteoarthritis: uncontrolled proteolysis in the wrong place. Semin Arthritis Rheum 2005; 34 (suppl. 2): 24-8.

[7] Hashimoto Y, Kakegawa H, Narita Y, et al. Significance of cathepsin B accumulation in synovial fluid of rheumatoid arthritis. Biochem Biophys Res Commun 2001; 283: 334-9.

[8] Halangk W, Lerch MM, Brandt-Nedelev B, et al. Role of cathepsin $B$ in intracellular trypsinogen activation and the onset of acute pancreatitis. J Clin Invest 2000; 106: 773-81.

[9] Murata M, Miyashita S, Yokoo C, et al. Novel epoxysuccinyl peptides. Selective inhibitors of cathepsin B, in vitro. FEBS Lett 1991; 280: 307-10.

[10] Towatari T, Nikawa T, Murata M, et al. Novel epoxysuccinyl peptides. A selective inhibitor of cathepsin $\mathrm{B}$, in vivo. FEBS Lett 1991; 280: 311-15.

[11] Buttle DJ, Murata M, Knight CG, Barrett AJ. CA074 methyl ester: a proinhibitor for intracellular cathepsin B. Arch Biochem Biophys 1992; 299: 377-80.

[12] Montaser M, Lalmanach G, Mach L. CA-074, but not its methyl ester CA-074Me, is a selective inhibitor of cathepsin B within living cells. Biol Chem 2002; 383: 1305-8.

[13] Hirumi H, Hirumi K, Dyole JJ, Cross GAM. In vitro cloning of animal-infective bloodstream forms of Trypanosoma brucei. Parasitology 1980; 80: 371-82.

[14] Baltz T, Baltz D, Giroud C, Crockett J. Cultivation in a semi-defined medium of animal infective forms of Trypanosoma brucei, T. equiperdum, T. evansi, T. rhodesiense and T. gambiense. EMBO J 1985; 4: 1273-7.
[15] Guaiquil VH, Farber CM, Golde DW, Vera JC. Efficient transport and accumulation of vitamin C in HL-60 cells depleted of glutathione. J Biol Chem 1997; 272: 9915-21.

[16] Gillmor SA, Craik CS, Fletterick RJ. Structural determinants of specificity in the cysteine protease cruzain. Protein Sci 1997; 6: 1603-11.

[17] Caffrey CR, Hansell E, Lucas KD, et al. Active site mapping, biochemical properties and subcellular localization of rhodesain, the major cysteine protease of Trypanosoma brucei rhodesiense. Mol Biochem Parasitol 2001; 118: 61-73.

[18] Musil D, Zucic D, Turk D, et al. The refined $2.15 \AA$ X-ray crystal structure of human liver cathepsin B: the structural basis for its specificity. EMBO J 1991; 10: 2321-30.

[19] Nägler DK, Tam W, Storer AC, Krupa JC, Mort JS, Ménard R. Interdependency of sequence and positional specificities for cysteine proteases of the papain family. Biochemistry 1999; 38: 4848-74.

[20] Meister A. Methods for the selective modification of glutathione metabolism and study of glutathione transport. Methods Enzymol 1985; 113: 571-85.

[21] Caffrey CR, Steverding D. Kinetoplastid papain-like cysteine peptidases. Mol Biochem Parasitol 2009; 167: 12-19.

[22] Barrett AJ, Kirschke H. Cathepsin B, cathepsin H, and cathepsin L. Methods Enzymol 1981; 80: 535-61.

[23] Otto HH, Schirmeister T. Cysteine proteases and their inhibitors. Chem Rev 1997; 97: 133-72.

(C) Dietmar Steverding; Licensee Bentham Open.

This is an open access article licensed under the terms of the Creative Commons Attribution Non-Commercial License (http://creativecommons.org/licenses/ by-nc/3.0/) which permits unrestricted, non-commercial use, distribution and reproduction in any medium, provided the work is properly cited. 